\title{
TRATAMENTOS PRÉ-GERMINATIVOS EM SEMENTES DE Myracrodruon urundeuva FREIRE ALLEMÃO ${ }^{1}$
}

\author{
Roberta Sales Guedes², Edna Ursulino Alves², Edilma Pereira Gonçalves³, Pedro Nóbrega Quintas \\ Colares $^{4}$, Matheus Serrano de Medeiros ${ }^{4}$ e Kelina Bernardo Silva ${ }^{5}$
}

\begin{abstract}
RESUMO - Este trabalho teve como objetivo determinar a metodologia mais eficiente para superação da dormência em sementes de Myracrodruon urundeuva. As sementes foram submetidas a 16 tratamentos: testemunha - sementes intactas ( $\left.\mathrm{T}_{1}\right)$; escarificação mecânica com lixa d'água $\mathrm{n}^{\circ} .80$ por $3,6 \mathrm{e} 9 \min \left(\mathrm{T}_{2}, \mathrm{~T}_{3}\right.$ e $\mathrm{T}_{4}$, respectivamente), imersão em ácido sulfúrico por 2, 4, 6, 8, 10 e $12 \min \left(\mathrm{T}_{5}, \mathrm{~T}_{6}, \mathrm{~T}_{7}, \mathrm{~T}_{8}, \mathrm{~T}_{9}\right.$ e $\mathrm{T}_{10}$, respectivamente), escarificação mecânica com lixa d'água ${ }^{\circ}$. 80, por 3, 6 e 9 min, seguida de embebição em água na temperatura ambiente por $24 \mathrm{~h}\left(\mathrm{~T}_{11}, \mathrm{~T}_{12}\right.$ e $\mathrm{T}_{13}$, respectivamente) e escarificação mecânica com lixa d'água n ${ }^{\circ}$. 80, por 3, 6 e 9 min, seguida de embebição em solução de nitrato de potássio $\left(\mathrm{KNO}_{3}\right)$ na temperatura ambiente por $24 \mathrm{~h}\left(\mathrm{~T}_{14}\right.$, $\mathrm{T}_{15}$ e $\mathrm{T}_{16}$, respectivamente). Os efeitos foram avaliados por meio de testes de emergência e de vigor (percentual de emergência, primeira contagem e índice de velocidade de emergência, comprimento e massa seca das plântulas). O delineamento utilizado foi o inteiramente ao acaso, com quatro subamostras de 25 sementes, sendo as médias comparadas pelo teste de Scott-Knott. Os resultados dos tratamentos envolvendo a embebição em água e em $\mathrm{KNO}_{3}$ não foram satisfatórios para superar a dormência de sementes de $M$. urundeuva. Constatou-se que houve diferença significativa entre os tratamentos em todas as variáveis avaliadas, e a dormência pôde ser superada eficientemente pela imersão em ácido sulfúrico por $12 \mathrm{~min}$.
\end{abstract}

Palavras-chave: Emergência, dormência, sementes florestais e planta medicinal.

\section{PRE-GERMINATION TREATMENTS IN Myracrodruon urundeuva FREIRE ALLEMÃO SEEDS}

\begin{abstract}
This study was carried out aiming at determining the most efficient methodology to overcome dormancy in Myracrodruon urundeuva seeds. The 16 treatments employed were: control - intact seeds $\left(T_{1}\right)$; mechanical scarification with sandpaper for 3,6 and 9 minutes $\left(T_{2}, T_{3}\right.$ and $T_{4}$, respectively), immersion in sulfuric acid pondered for $2,4,6,8,10$ and 12 minutes $\left(T_{5}, T_{6}, T_{7}, T_{8}, T_{9}\right.$ and $T_{10}$, respectively), mechanical scarification with sandpaper of water number. 80, for 3, 6 and 9 minutes, followed by immersion in water at room temperature during 24 hours $\left(T_{11}, T_{12}\right.$ and $T_{13}$, respectively) and mechanical scarification with sandpaper of water number. 80, for 3, 6 and 9 minutes followed by immersion in solution of potassium nitrate ( $\left.\mathrm{KNO}_{3}\right)$ at room temperature during 24 hours $\left(T_{14}, T_{15}\right.$ and $T_{16}$, respectively). The effects were appraised through emergency and of vigor tests (percentile of emergency, first count and index of emergency speed, length and mass evaporates of the seedlings). It was used a completely randomized experimental design with four replicates of 25 seeds and the averages were compared through the Scott - Knott test. The treatments that involvd water and $\mathrm{KNO}_{3}$ soaking were notsatisfactory to overcome the dormancy of seeds of $\mathrm{M}$. urundeuva. There were significant differences among the treatments for all variables and the most efficient treatment to overcome dormancy was the immersion in sulfuric acid for 12 minutes.
\end{abstract}

Keywords: emergence, dormancy, forest seeds and medicinal plant.

\footnotetext{
${ }^{1}$ Recebido em 06.05.2008 e aceito para publicação em 23.06.2009.

${ }^{2}$ Departamento de Fitotecnia da UFPB, Areia-PB. E-mail: <roberta_biologa09@yahoo.com.br>e <ednaursulino@cca.ufpb.br>.

${ }^{3}$ Departamento de Agronomia da Universidade Federal Rural de Pernambuco (UFRPE). E-mail: <edilmapg@ hotmail.com>.

${ }^{4}$ Graduação em Agronomia da Universidade Federal da Paraíba (UFPB). E.mail: <serrano1205@ hotmail.com>.

${ }^{5}$ Programa de Pós-Graduaçãoem Agronomia. Universidade Federal da Paraíba, UFPB, Brasil. E-mail: <kelinabernardo@ yahoo.com.br>.
} 


\section{INTRODUÇÃO}

A aroeira-do-sertão (Myracrodruon urundeuva Fr. All) é uma espécie arbórea pertencente à família Anacardiaceae, cuja distribuição natural limita-se à América do Sul, é nativa no Brasil e mais amplamente distribuída nas Regiões Nordeste, Sudeste e CentroOeste (CARMELO-GUERREIRO e PAOLI, 1999). Devido à alta resistência mecânica da madeira, a espécie é largamente utilizada na construção civil (LORENZI, 1992) e na arborização de ruas e praças, bem como apresenta casca rica em tanino, sendo muito utilizada em curtumes e também utilizada na medicina popular (LORENZI, 1992; ALBUQUERQUE et al., 2004).

Comparada com outras espécies com características nobres e alto valor econômico, a $M$. urundeuva tem sua exploração predatória extensiva, acarretando o comprometimento de suas populações naturais, e, portanto, requer estudos para garantir sua conservação. Em decorrência dessa ampla utilidade e exploração, a espécie foi incluída na lista oficial do IBAMA como uma espécie ameaçada de extinção, na categoria vulnerável (IBAMA, 1992).

As sementes constituem a via de propagação mais empregada na implantação de plantios, devido ao fato de ser um meio rápido e geralmente não dispendioso, sendo de fundamental interesse o estudo de vários fatores que interferem na propagação, principalmente a germinação e vigor, que influem de forma direta na dispersão das espécies. As sementes ortodoxas, como as de $M$. urundeuva, toleram a secagem até a redução do seu teor de água para valores inferiores a 23\% (base úmida) e, dessa forma, têm o metabolismo reduzido até níveis que favorecem a conservação da qualidade fisiológica, entrando, portanto, num estágio de dormência.

A dormência é o fenômeno pelo qual sementes de determinada espécie, mesmo sendo viáveis e tendo todas as condições ambientais favoráveis para tanto, não germinam. Tais sementes requerem tratamentos pré-germinativos para aumentar a percentagem de germinação (CARVALHO e NAKAGAWA, 2000). Diversos fatores podem induzir à dormência das sementes como impermeabilidade do tegumento à água e aos gases, embriões imaturos ou rudimentares, presença de substâncias promotoras ou inibidoras de crescimento, exigências especiais de luz ou de temperatura, entre outras (CARVALHO e NAKAGAWA, 2000).
Entre os métodos empregados para superação da dormência, a escarificação mecânica é uma técnica frequentemente utilizada e constitui a opção mais prática, de baixo custo e eficaz para promover rápida e uniforme germinação. No entanto, deve ser efetuada com muito cuidado, para evitar que a escarificação excessiva cause danos ao tegumento e diminua a germinabilidade (McDONALD e COPELAND, 1997). A escarificação mecânica do tegumento foi eficiente na superação da dormência das sementes de várias espécies com tegumento impermeável, como as sementes de Bowdichia virgilioides Kunth (SMIDERLE e SOUSA, 2003), Sterculia foetida L. (SANTOS et al., 2004), Bauhinia divaricata L. (ALVES et al., 2004), Peltophorum dubium (Spreng.) Taub. (PIROLI et al., 2005), Desmanthus virgatus Willd. (ARAÚJO et al., 2008), Ipomoea purga Wender (GUEDES et al., 2008) e Erythrina velutina Willd. (SILVA, 2008).

A escarificação química com ácidos é amplamente usada, mas deve ser aplicada com certo cuidado, uma vez que longos períodos de exposição causam danos às sementes e, consequentemente, redução de germinação (EGLEY, 1972). A escarificação com ácidos foi empregada com eficiência na superação da dormência de sementes Bowdichia virgilioides Kunth (SMIDERLE e SOUSA, 2003), Tachigalia multijuga (Benth.) (LIMA e BORGES et al., 2004), Zizyphus joazeiro Mart. (ALVES et al., 2006), Ormosia nitida Vog. (LOPES et al., 2006), Merremia aegyptia L. (PEREIRA et al., 2007) e Acacia mangium Willd. (RODRIGUES et al., 2008).

Esses métodos, além de aumentarem a permeabilidade à água, podem induzir outras mudanças, como aumento da sensibilidade à luz e temperatura, permeabilidade aos gases, remoção de inibidores e promotores, injúria aos tecidos, todos com significante influência no metabolismo da semente e, consequentemente, na dormência (KHAN, 1977). Entretanto, a aplicação e eficácia desses tratamentos dependem da causa e do grau de dormência, o que é bastante variável entre as espécies (LIMA e GARCIA, 1996).

Este trabalho teve como objetivo determinar metodologias para superação da dormência em função da necessidade de uniformizar a germinação de sementes de $M$. Urundeuva, considerando que há poucas informações a esse respeito na literatura. 


\section{MATERIAL E MÉTODOS}

A pesquisa foi conduzida no Laboratório de Análises de Sementes do Centro de Ciências Agrárias da Universidade Federal da Paraíba, entre fevereiro e março de 2008. Foram utilizadas sementes de Myracrodruon urundeuva, coletadas em oito árvores-matriz, no Município de Soledade, PB, as quais foram conduzidas ao laboratório, beneficiadas manualmente e mantidas em ambiente protegido, para secagem natural por cinco dias.

Neste estudo, as drupas de M. urundeuva, caracterizadas por Carmello-Guerreiro e Paoli (1999) como frutos globosos, pequenos, resinosos, contendo apenas um putâmen, foram referidas como sementes, para facilitar a compreensão do texto.

Depois de beneficiadas, as sementes foram submetidas a diferentes tratamentos para superação da dormência: testemunha $=$ sementes intactas $\left(\mathrm{T}_{1}\right)$; escarificação mecânica manual com lixa d'água $n^{\circ} .80$, por 3,6 e 9 $\min \left(\mathrm{T}_{2}, \mathrm{~T}_{3}\right.$ e $\mathrm{T}_{4}$, respectivamente); imersão em ácido sulfúrico por $2,4,6,8,10$ e $12 \min \left(\mathrm{T}_{5}, \mathrm{~T}_{6}, \mathrm{~T}_{7}, \mathrm{~T}_{8}, \mathrm{~T}_{9}\right.$ e $\mathrm{T}_{10}$, respectivamente); escarificação mecânica manual com lixa d'água $n^{\circ}$. 80, por 3, 6e 9 min, seguida de embebição em água à temperatura ambiente por $24 \mathrm{~h}\left(\mathrm{~T}_{11}, \mathrm{~T}_{12} \mathrm{e}\right.$ $\mathrm{T}_{13}$, respectivamente) e escarificação mecânica manual com lixa d'água $n^{\circ}$. 80, por 3, 6 e 9 minutos, seguida de embebição em solução de nitrato de potássio $\left(\mathrm{KNO}_{3}\right)$ à temperatura ambiente por 24 horas $\left(\mathrm{T}_{14}, \mathrm{~T}_{15}\right.$ e $\mathrm{T}_{16}$, respectivamente). Na escarificação mecânica manual, as sementes foram postas entre duas folhas de lixa d'água $n^{\circ} .80$ e, em seguida, friccionadas lentamente, realizando-se movimentos circulares a uma velocidade constante, a fim de escarificar uniformemente as sementes. As sementes imersas em ácido sulfúrico foram constantemente revolvidas com um bastão de vidro, objetivando uniformizar a sua ação abrasiva. Decorridos os períodos preestabelecidos, as sementes foram lavadas em água corrente, por $10 \mathrm{~min}$, para que os resíduos do ácido fossem totalmente retirados.

Após a aplicação dos tratamentos as sementes foram submetidas ao teste de emergência em casa de crescimento, as quais foram semeadas em bandejas plásticas perfuradas no fundo, contendo areia lavada, previamente esterilizada em autoclave, umedecida com quantidade de água equivalente a $60 \%$ da capacidade de retenção, cuja manutenção da umidade foi realizada por meio de irrigações diárias. Foram avaliadas as seguintes características:

\subsection{Emergência}

Foram utilizadas 100 sementes por tratamento, divididas em quatro subamostras de 25 sementes. As contagens foram realizadas dos 4 aos 21 dias após a instalação do teste, utilizando como critério o de plântulas emergidas e com os cotilédones acima do substrato, respectivamente; primeira contagem de emergência correspondente à porcentagem acumulada de plântulas normais até o $10^{\circ}$ dia após o início do teste.

\section{2. Índice de velocidade de emergência (IVE)}

Foram realizadas contagens diárias, durante 21 dias, das plântulas emergidas, sendo o índice calculado conforme a fórmula proposta por Maguire (1962).

\subsection{Comprimento e massa seca de plântulas}

No final dos testes de emergência, as plântulas normais de cada repetição foram medidas com régua graduada em centímetro, sendo os resultados expressos em cm/plântula. Após as medições, as plântulas foram colocadas em sacos de papel e levadas à estufa regulada a $65{ }^{\circ} \mathrm{C}$, por $48 \mathrm{~h}$. Decorrido esse período, o material foi pesado em balança analítica com precisão de $0,001 \mathrm{~g}$, cujos resultados foram expressos em g/plântula.

\subsection{Delineamento experimental}

Foi utilizado o delineamento inteiramente casualizado, constando de 16 tratamentos. Os dados em percentagem, transformados em Arcoseno ( $(x+a) / 100)^{1 / 2}$, foram submetidos à análise de variância, sendo a comparação entre as médias feita pelo teste de Scott-Knott a 5\% de probabilidade.

\section{RESULTADOS E DISCUSSÃO}

Na Figura 1, apresentam-se os dados relativos à emergência, na qual se observa que as sementes submetidas ao tratamento $\mathrm{T}_{10}$ (imersão em ácido sulfúrico por $12 \mathrm{~min}$ ) foram responsáveis pelos maiores percentuais de emergência de plântulas (74\%). Já os tratamentos que envolviam a embebição em água e em $\mathrm{KNO}_{3}\left(\mathrm{~T}_{11}\right.$, $\mathrm{T}_{12}, \mathrm{~T}_{13}, \mathrm{~T}_{14}, \mathrm{~T}_{15}$ e $\mathrm{T}_{16}$, respectivamente) apresentaram os menores percentuais de emergência. Dados semelhantes foram constatados por Lopes et al. (2006) em sementes de Ormosia nitida Vog., as quais mostraram os menores percentuais de germinação quando submetidas à escarificação seguida de embebição em água por 24 h.

R. Árvore, Viçosa-MG, v.33, n.6, p997-1003, 2009 


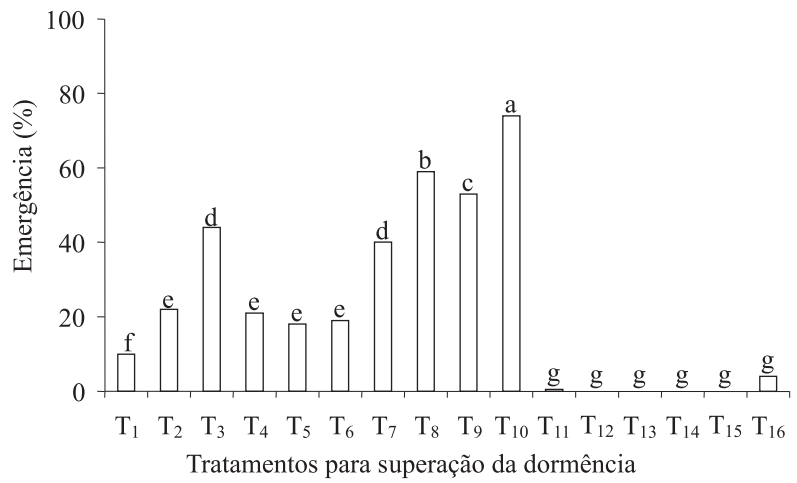

Figura 1 - Emergência de plântulas de Myracrodruon urundeuva Fr. All. submetidas a tratamentos para superar a dormência. Médias seguidas pela mesma letra não diferem entre si, pelo teste de Scott-Knott a 5\% de probabilidade.

Figure 1 - Emergence of Myracrodruon urundeuva Fr. All. seedlings submitted to treatments to overcome dormancy.

A redução na porcentagem de emergência de plântulas oriundas dos tratamentos $\mathrm{T}_{11}, \mathrm{~T}_{12}, \mathrm{~T}_{13}, \mathrm{~T}_{14}$, $\mathrm{T}_{15}$ e $\mathrm{T}_{16}$ pode estar relacionada aos efeitos danosos da lixa, uma vez que a escarificação mecânica propicia a degradação do tegumento e o aumento do período de fricção pode causar ruptura das células essenciais, o que favorece as injúrias mecânicas e a invasão de fungos, prejudicando, assim, a emergência. A embebição, possivelmente, pode também ter sido o fator limitante para a emergência. Castro et al. (2004) relataram que as sementes, quando colocadas para embeber, podem sofrer danos irreversíveis no nível do sistema de membranas, o que leva à lixiviação de conteúdos celulares, afetando negativamente a germinação.

A eficácia do ácido sulfúrico para superar a dormência tegumentar também foi demonstrada em sementes de outras espécies, a exemplo da Bowdichia virgilioides Kunth., com a imersão no ácido sulfúrico por 5 min (SMIDERLE e SOUSA, 2003), Zizyphus joazeiro Mart., com a imersão entre os períodos de 74 e 115 min (ALVES et al., 2006), Ormosia nitida Vog., com a imersão no ácido por 10 min (LOPES et al., 2006), Merremia aegyptia L., com a imersão em ácido sulfúrico por 10 min (PEREIRA et al., 2007) e Acacia mangium Willd., com a imersão no ácido por $90 \mathrm{~min}$ (RODRIGUES et al., 2008).

$\mathrm{O}$ tratamento $\mathrm{T}_{3}$ (escarificação mecânica manual sem embebição por $6 \mathrm{~min}$ ), embora provoque fissuras no tegumento, aumentando a permeabilidade das

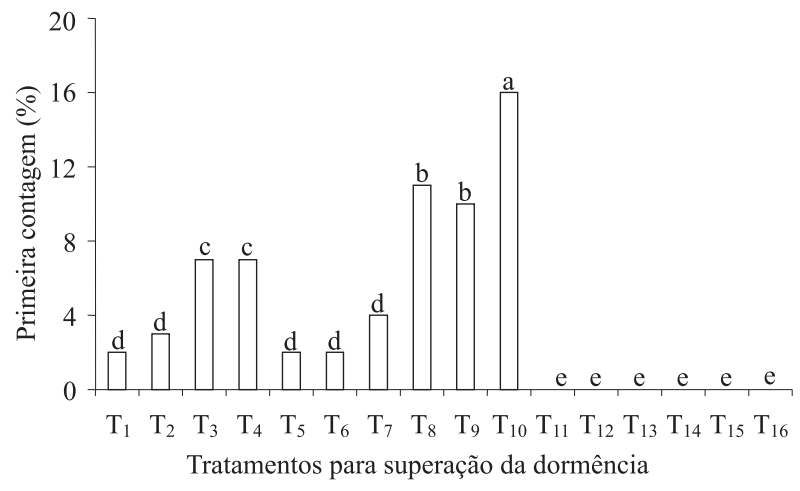

Figura 2 - Primeira contagem de emergência de plântulas de Myracrodruon urundeuva Fr. All. submetidas a tratamentos para superar a dormência. Médias seguidas pela mesma letra não diferem entre si, pelo teste de Scott-Knott a 5\% de probabilidade.

Figure 2 - First count of emergence of Myracrodruon urundeuva Fr. All. seedlings submitted to treatments to overcome dormancy.

sementes e permitindo a embebição e o início do processo de germinação, não se mostrou eficiente na superação da dormência de Myracrodruon urundeuva, no entanto se mostrou eficiente em relação à testemunha $\left(\mathrm{T}_{1}\right)$. Dados semelhantes foram observados por Franke e Baseggio (1998) na superação da dormência de sementes de Desmodium incanum DC. e Lathyrus nervosus Lam. e por Santos et al. (2004) para sementes de Sterculia foetida L. Acredita-se que a fricção manual não tenha sido suficientemente uniforme, fazendo que muitas sementes escapassem do atrito com a lixa.

Para sementes de Peltophorum dubium (Spreng.) Taub., a escarificação mecânica do lado oposto da emergência da radícula foi eficiente para superar a dormência (PIROLI et al., 2005). A escarificação manual também foi eficiente para quebrar a dormência de sementes de Trifolium riograndense Burkart e Desmanthus depressus Humb. (SUÑ́́ e FRANKE, 2006). Araújo et al. (2008) constataram que o método mais eficaz para superar a dormência de sementes de Desmanthus virgatus Willd. foi a escarificação manual com lixa d'água $\mathrm{n}^{\circ}$. 80. Já na sementes de Ipomoea purga Wender a escarificação com lixa ${ }^{\circ} 80$, seguida de embebição em água durante 24,48 e $72 \mathrm{~h}$, a temperatura ambiente foi o método mais eficiente para superação da dormência (GUEDES et al., 2008).

Os dados referentes ao vigor, determinado pela primeira contagem de emergência, são apresentados na Figura 2. À semelhança da percentagem de emergência, 


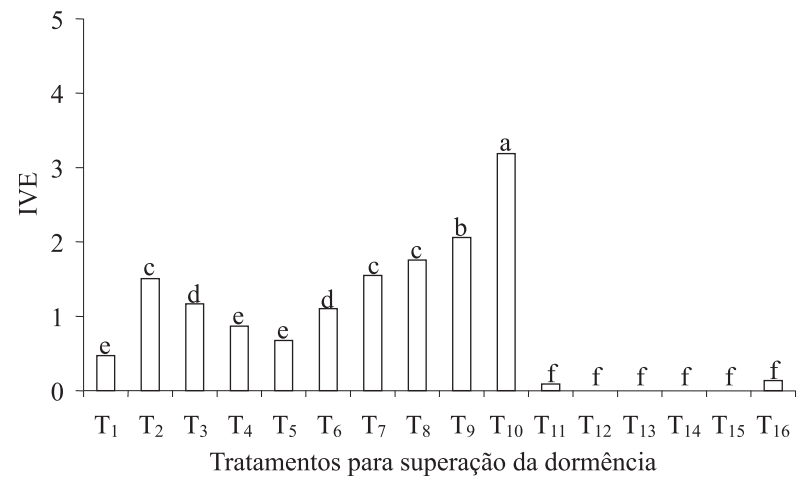

Figura 3 - Índice de velocidade de emergência (IVE) de plântulas de Myracrodruon urundeuva Fr. All submetidas a tratamentos para superar a dormência. Médias seguidas pela mesma letra não diferem entre si, pelo teste de Scott-Knott a 5\% de probabilidade.

Figure 3-Emergence speed index (ESI) of Myracrodruon urundeuva Fr. All. seedlings submitted to treatments to overcome dormancy.

os maiores percentuais de plântulas na primeira contagem também foram obtidos de sementes oriundas do tratamento $\mathrm{T}_{10}$ (imersão em ácido sulfúrico por $12 \mathrm{~min}$ ). Enquanto os tratamentos $\mathrm{T}_{11}, \mathrm{~T}_{12}$ e $\mathrm{T}_{13}$ (escarificação mecânica com lixa d'água n ${ }^{\circ} .80$, por 3,6 e 9 min, seguida de embebição em água) e $\mathrm{T}_{14}, \mathrm{~T}_{15}$ e $\mathrm{T}_{16}$ (escarificação mecânica com lixa d'água $\mathrm{n}^{\circ}$. 80 , por 3,6 e 9 min, seguida de embebição em $\mathrm{KNO}_{3}$ por $24 \mathrm{~h}$ ) demonstram as menores porcentagens de emergência por ocasião da primeira contagem (Figura 2).

A imersão em água à temperatura ambiente por 24 h também foi responsável por baixos percentuais de emergência, por ocasião da primeira contagem em sementes de Cassia excelsa Scharad (JELLER e PEREZ, 1999), Bauhinia divaricata L. (ALVES et al., 2004) e Merremia aegyptia L. (PEREIRA et al., 2007).

A eficiência do ácido sulfúrico também foi constatada na primeira contagem de emergência de sementes de Zizyphus joazeiro Mart. (ALVES et al., 2006) e Acacia mangium Willd. (RODRIGUES et al., 2008).

Quanto ao índice de velocidade de emergência (Figura 3), verificou-se que o tratamento $\mathrm{T}_{10}$ (imersão em ácido sulfúrico por $12 \mathrm{~min}$ ) foi responsável pelo vigor máximo das sementes. O tratamento com ácido sulfúrico foi responsável pelos maiores índice de velocidade de emergência em sementes de Bowdichia virgilioides H.B.K. quando imersas por períodos entre 8 e 11 min (SAMPAIO et al., 2001), em sementes de

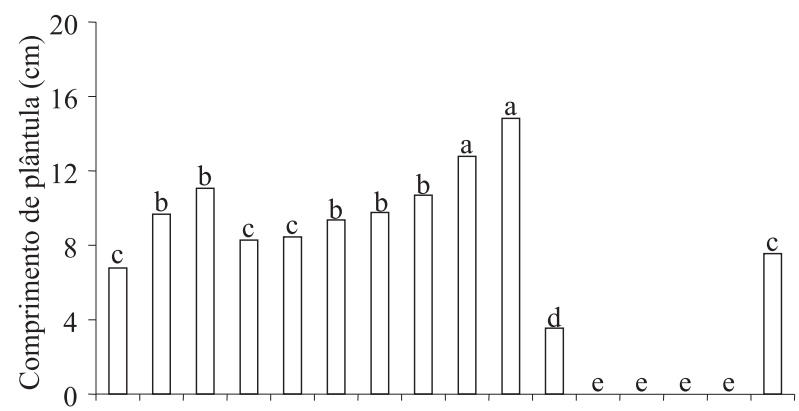

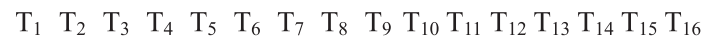
Tratamentos para superação da dormência

Figura4-Comprimento de plântulas de Myracrodruon urundeuva Fr. All submetidas a tratamentos para superar a dormência. Médias seguidas pela mesma letra não diferem entre si, pelo teste de Scott-Knott a 5\% de probabilidade.

Figure 4-Length of Myracrodruon urundeuva Fr. All. seedlings submitted to treatments to overcome dormancy.

Ormosia nitida Vog. quando imersas por $10 \mathrm{~min}$ (LOPES et al., 2006), também em sementes de Merremia aegyptia L., com imersão por $10 \mathrm{~min}$ (PEREIRA et al., 2007) e Acacia mangium Willd., com imersão no ácido por períodos de 90 e 60 min (RODRIGUES et al., 2008).

Os tratamentos $\mathrm{T}_{2}$ (escarificação mecânica manual com lixa $\mathrm{n}^{\circ} .80$ por 3 min) e os tratamentos $\mathrm{T}_{7}$ e $\mathrm{T}_{8}$ (imersão em ácido sulfúrico por 6 e 8 min, respectivamente) não diferiram estatisticamente entre si. A escarificação com lixa proporcionou os maiores índices de velocidade de emergência em semente de Caesalpinia pyramidalis Tul. (ALVES et al., 2007).

Quando as sementes foram submetidas aos tratamentos $\mathrm{T}_{9}$ e $\mathrm{T}_{10}$ (imersão em ácido 10 e $12 \mathrm{~min}$, respectivamente), originaram plântulas com maior comprimento (Figura 4), seguidos dos tratamentos $\mathrm{T}_{2}$ e $\mathrm{T}_{3}$ (escarificação mecânica manual com lixa $\mathrm{n}^{\mathrm{o}}$. 80 por 3 e 6 min, respectivamente), $\mathrm{T}_{6}, \mathrm{~T}_{7}$ e $\mathrm{T}_{8}$ (imersão em ácido sulfúrico por 4, 6 e $8 \mathrm{~min}$, respectivamente), que não diferiram estatisticamente. A imersão em ácido sulfúrico, por períodos prolongados, prejudicou o desenvolvimento das plântulas de Bowdichia virgilioides H.B.K. (SAMPAIO et al., 2001) e Zizyphus joazeiro Mart. (ALVES et al., 2006). Em sementes de Merremia aegyptia L., a escarificação mecânica e a imersão em ácido sulfúrico por 6 min produziram mudas com maior altura de plântulas (PEREIRA et al., 2007).

R. Árvore, Viçosa-MG, v.33, n.6, p997-1003, 2009 




Figura 5 - Massa seca de plântulas de Myracrodruon urundeuva Fr. All. submetidas a tratamentos para superação da dormência. Médias seguidas pela mesma letra não diferem entre si, pelo teste de Scott-Knott a $5 \%$ de probabilidade.

Figure 5 - Dry mass of Myracrodruon urundeuva Fr. All. seedlings submitted to treatments to overcome dormancy.

Na Figura 5 estão os dados relativos à massa seca das plântulas, pelos quais se verificou que o tratamento $\mathrm{T}_{10}$ (imersão em ácido sulfúrico por $12 \mathrm{~min}$ ) originou plântulas com maior conteúdo de massa seca, enquanto os tratamentos $\mathrm{T}_{12}$ e $\mathrm{T}_{13}$ (escarificação mecânica manual com lixa d'água $\mathrm{n}^{\circ}$. 80, por 6 e 9 min, seguida de embebição em água), $\mathrm{T}_{14}$ e $\mathrm{T}_{15}$ (escarificação mecânica com lixa d'água $\mathrm{n}^{\circ}$. 80, por 3 e 6 min, seguida de embebição $\mathrm{KNO}_{3}$ por $24 \mathrm{~h}$ ) foram responsáveis pelos menores conteúdos de massa seca de plântulas de M. urundeuva.

O ácido sulfúrico foi responsável pelo maior conteúdo de massa seca em sementes de Bowdichia virgilioides H.B.K. (SAMPAIO et al., 2001) e Zizyphus joazeiro Mart. (ALVES et al., 2006). Diferentemente do que foi observado neste trabalho, Santos et al. (2004) verificaram que as plântulas de Sterculia foetida L., provenientes de sementes escarificadas e embebidas, apresentaram maior massa seca.

\section{CONCLUSÃO}

Para superação da impermeabilidade do tegumento de sementes de Myracrodruon urundeuva, recomendase a imersão em ácido sulfúrico por $12 \mathrm{~min}$.

\section{REFERÊNCIAS}

ALBUQUERQUE, R. J. M.; RODRIGUES, L. V.; VIANA, G. S. B. Análise clínica e morfológica da conjuntivite alérgica induzida por ovalbumina e tratada com chalcona em cobaias. Acta Cirúrgica Brasileira, v.19, n.1, p.43-68, 2004.

R. Árvore, Viçosa-MG, v.33, n.6, p.997-1003, 2009
ALVES, A. U. et al. Superação da dormência em sementes de Bauhinia divaricata L. Acta Botanica Brasilica, v.18, n.4, 871-879, 2004.

ALVES, E. U. et al. Ácido sulfúrico na superação da dormência de unidades de dispersão de juazeiro (Zizyphus joazeiro Mart.). Revista Árvore, v.30, n.2, p.187-195, 2006.

ALVES, E. U. et al. Superação da dormência de sementes de Caesalpinia pyramidalis Tul. Revista Árvore, v.31, n.3, p.405-415, 2007.

ARAÚJO, E. R. et al. Superação de dormência em sementes de Desmanthus virgatus Willd. In: CONGRESSO DE PESQUISA E INOVAÇÃO DA REDE NORTE NORDESTE DE EDUCAÇÃO TECNOLÓGICA, 3., 2008, Fortaleza. Resumos... Fortaleza: 2008.

CARMELLO-GUERREIRO, S. M.; PAOLI, A. A. S. Aspectos morfológicos anatômicos da semente de aroeira (Myracrodruon urundeuva Fr. Allem. Anacardiaceae), com notas sobre paquicalaza. Revista Brasileira de Sementes, v.21, n.1, p.222-228, 1999.

CARVAlho, N. M.; NAKAGAWA, J. Sementes: ciência, tecnologia e produção. 4.ed. Jaboticabal: Funep, 2000. 588p.

CASTRO, R. D.; BRADFORD, K. J.; HILHOSRT, H. W. M. Embebição e reativação do metabolismo. In: FERREIRA, A. G.; BORGHETI, F.

Germinação: do básico ao aplicado. Porto Alegre: Artmed, 2004. p.149-162.

EGLEY, G. H. Influence of the seed envelope and growth regulators upon seed dormancy in witchweed (Stringa lutea Lour.). Annals of Botany, v.36, n.147, p.755-770, 1972.

FRANKE, L. B.; BASEGGIO, J. Superação da dormência de sementes de Desmodium incanum DC. e Lathyrus nervosus Lam. Revista Brasileira de Sementes, v.20, n.2, p.420-424, 1998.

GUEDES, R. S. et al. Superação da dormência de Ipomoea purga Wender. In: CONGRESSO DE PESQUISA E INOVAÇÃO DA REDE NORTE NORDESTE DE EDUCAÇÃO TECNOLÓGICA, 3., 2008, Fortaleza. Resumos... Fortaleza: 2008. 
IBAMA. Portaria 006/92-N.Lista oficial das espécies da flora ameaçadas de extinção. Diário Oficial, de 15 de janeiro de 1992.

JELLER, H.; PEREZ, S. C. J. G. A. Estudo da superação da dormência e da temperatura em sementes de Cassia excelsa Schrad. Revista Brasileira de Sementes, v.21, n.1, p.32-40, 1999.

KHAN, A. A. Seed dormancy: concepts and theories. In: KHAN, A. A. The physiology and biochemistry of seed dormancy and germination. Amsterdan: North-Holland Publishing Company, 1977. p. 29-50.

LIMA e BORGES, E. E. et al. Alterações fisiológicas em sementes de Tachigalia multijuga (Benth.) (Mamoneira) relacionadas aos métodos para a superação da dormência. Revista Árvore, v.28, n.3, p.317- 325, 2004.

LIMA, D.; GARCIA, L. C. Avaliação de métodos para o teste de germinação em sementes de Acacia mangium Willd. Revista Brasileira de Sementes, v.18, n.2, p.180-185, 1996.

LOPES, J. C.; DIAS, P. C.; MACEDO, C. M. P. Tratamentos para acelerar a germinação e reduzir a deterioração das sementes de Ormosia nitida Vog. Revista Árvore, v.30, n.2, p.171-177, 2006.

LORENZI, H. Árvores brasileiras: manual de identificação e cultivo de plantas arbóreas nativas do Brasil. Nova Odessa: Plantarum, 1992. 382p.

MAGUIRE, J. D. Speed of germination aid in selection and evaluation for seedling emergence and vigor. Crop Science, v.2, n.2, p.176-177, 1962.

McDONALD, M. B.; COPELAND, L. O. Seed production: principles and practices. New Jersey: Chapmam \& Hall, 1997. 749p.
PEREIRA, E. W. L. et al. Superação de dormência em sementes de jitirana (Merremia aegyptia L.). Revista Caatinga, v.20, n.2, p.59-62, 2007.

PIROLI, E. L. et al. Germinação de sementes de canafístula Peltophorum dubium (Spreng.) Taub. tratadas para superação da dormência.

Colloquium Agrariae, v.1, n.1, p.13-18, 2005.

RODRIGUES, A. P. D. C. et al. Tratamentos para superar a dormência de sementes de Acacia mangium Willd. Acta Scientiarum Agronomy, v.30, n.2, p.279-283, 2008.

SAMPAIO, S. L. V.; PEIXOTO, C. V.; PEIXOTO, M. F. S. P. Ácido sulfúrico na superação da dormência de sementes de sucupira-preta (Bowdichia virgilioides H.B.K. - Fabaceae). Revista Brasileira de Sementes, v.23, n.1, p.184-190, 2001.

SANTOS, T. O.; MORAIS, T. G. O.; MATOS, V. P. M. Escarificação mecânica em sementes de chichá (Sterculia foetida L.). Revista Árvore, v.28, n.1, p.1-6, 2004.

SILVA, K. B. Tratamentos prégerminativos em sementes de Erythrina velutina Willd. 2008. 128f. Dissertação (Mestrado em Agronomia) - Universidade Federal da Paraíba, Areia, 2008.

SMIDERLE, O. J.; SOUSA, R. C. P. Dormência em sementes de paricarana (Bowdichia virgilioides Kunth -Fabaceae - Papilionoideae). Revista Brasileira de Sementes, v.25, n.1, p.72-75, 2003.

SUÑÉ, A. D.; FRANKE, L. B. Superação de dormência e metodologias para testes de germinação em sementes de Trifolium riograndense Burkart e Desmanthus depressus Humb. Revista Brasileira de Sementes, v.28, n. 3, p.29-36, 2006. 
